\title{
Infection with Mayaro virus in a French traveller returning from the Amazon region, Brazil, January, 2010
}

M C Receveur ${ }^{1}$, M Grandadam², T Pistone ${ }^{1}$, D Malvy (denis.malvy@chu-bordeaux.fr) ${ }^{1}$

1. Travel clinics and Division of Tropical Medicine and Imported Diseases, Department of Internal Medicine and Tropical

Diseases, Hôpital St-André, University Hospital Centre, Bordeaux, France

2. Centre national de référence des arbovirus, Institut Pasteur, Paris, France

Citation style for this article:

Citation style for this article: Receveur MC, Grandadam M, Pistone T, Malvy D. Infection with Mayaro virus in a French traveller returning from the Amazon region, Brazil, January, 2010. Euro Surveill. 2010;15(18):pii=19563. Available online: http://www.eurosurveillance.org/ViewArticle.aspx?Articleld=19563

This article has been published on 6 May 2010

Mayaro virus (MAYV) disease is a mosquito-borne zoonosis endemic in humid forests of tropical South America. MAYV is closely related to other alphaviruses that produce a dengue-like illness accompanied by long-lasting arthralgia. A French tourist developed high-grade fever and severe joint manifestations following a 15-day trip in the Amazon basin, Brazil, and was diagnosed with MAYV infection in January 2010. This case is the first reported in a traveller returning from an endemic South American country to Europe.

\section{Introduction}

Mayaro virus (MAYV) (family Togaviridae, genus Alphavirus) is an arthropod-borne zoonotic pathogen circulating only in tropical South America [1]. The transmission cycle of MAYV in the wild is nearly similar to the continuous sylvatic cycle of yellow fever and is believed to involve wild primates (monkeys) as the reservoir and the tree-canopy-dwelling Haemagogus mosquito as the vector. Thus, human infections are strongly associated with recent exposure to humid tropical forest environments $[1,2]$. MAYV disease is an acute, self-limited dengue-like illness of three to five days' duration. Moreover, MAYV is closely related to chikungunya virus and produces a nearly indistinguishable, highly debilitating arthralgic disease [1-3].

Here we report the case of MAYV disease that recently occurred in a French citizen who presented with severe rheumatologic disorders after visiting the Brazilian Amazon. This report illustrates that with increasing travel to remote areas, travellers are at risk of acquiring and importing rare diseases that are not indigenous to Europe.

\section{Case report}

The patient, a man in his late 20s, came to the travel clinic of the Department of Internal Medicine and Tropical Diseases of the University Hospital Centre, Bordeaux, France on 4 January 2010 with persistent incapacitating arthralgia for a two-month period and predominating in his knees and joints of the hands.

\section{FIGURE}

Timeline for travel history and symptoms in a French traveller with Mayaro virus disease, October 2009 - January 2010

\begin{tabular}{|c|c|c|c|c|c|c|}
\hline \multirow{2}{*}{$\begin{array}{r}\text { Wo } \\
23 / 10 / 09\end{array}$} & & $W_{1}$ & $W_{2}$ & $W_{10}$ & $W_{15}$ & W23 \\
\hline & $25 / 10 / 09$ & $27 / 10 / 09$ & $05 / 11 / 09$ & $05 / 01 / 10$ & $08 / 02 / 10$ & $10 / 04 / 10$ \\
\hline \multirow[t]{3}{*}{ Manaus } & Barcelos & Rio Negro & Barcelos & Admission & & \\
\hline & & area, & Return & & & \\
\hline & & Forest & & & & \\
\hline
\end{tabular}

$\begin{aligned} & \text { Febrile } \\ & \text { polyarthritis }\end{aligned}$
$\begin{aligned} & \text { Severe } \\ & \text { arthralgia and } \\ & \text { incapacitation }\end{aligned}$
$\begin{aligned} & \text { 1 st serum sample } \\ & \text { MAYV IgM+ }\end{aligned}$
2nd serum sample


The patient had travelled in the Amazon forest region for two weeks in October and November 2009 for the purpose of fishing and butterfly hunting. He stayed for two days in Manaus, Amazonas, Brazil, and for a further two days at Barcelos, Amazonas, north-western Brazil, before travelling in a dugout canoe along the Rio Negro River for ten days to the confluence area of the Demini River with the Araca River, a forest place situated 70 miles north of Barcelos. After another two days in Barcelos, he returned to France via Manaus and Sao Paulo (Figure).

During his second stay in Barcelos, in early November, he developed symptoms assumed to be related to dengue virus infection, with high-grade fever, headache, generalised myalgia and diffuse arthralgia. Macular and partially confluent transient exanthema mainly on his arms appeared around the fifth day of illness. After his return to France, the patient had increasingly difficulty walking and was severely impaired in daily activities because of severe recurrent joint pains.

The patient had received yellow fever vaccine 10 years before. During the trip to the Amazon, he had taken doxycyclin as prophylaxis for malaria.

When he presented to our centre on 5 January 2010 (two months after onset of symptoms), the patient complained of persistent headache, myalgia and severe symmetrical joint pains (wrists and ankles). At the time of presentation, laboratory tests showed a leukocyte cell count of 6,600 cells $/ \mu \mathrm{L}$ and a thrombocyte count of 177,000 platelets $/ \mu \mathrm{L}$. No markers of autoimmunity were found, notably anti-citrullin peptide antibodies or antinuclear antibodies. He was negative for the major histocompatibility complex HLA B27 gene. Concurrently, serologic status for dengue, chikungunya and yellow fever viruses as well as MAYV was evaluated using IgM capture and IgG sandwich ELISA at the National Reference Centre for Arboviruses, Institut Pasteur, Paris. Serology for MAYV revealed positive results for specific IgM (optical density $[O D]=0.34$; serum control $O D=0.122)$. $O D$ values for specific IgG were negative $(O D=0.082$; serum control $O D=0.092)$. The other serological results were negative, as well as tests for leptospirosis, rickettsiosis, Q fever, cytomegalovirus and Plasmodium falciparum malaria. Five weeks later, on 8 February 2010, MAYV antibody serology showed persistence of specific IgM $(O D=0.494$; serum control $O D=0.116)$ and a lack of immunoglobulin switching from IgM to IgG (OD for IgG $=0.076$; serum control $\mathrm{OD}=0.084$ ).

The patient recovered completely, although severe joint pain persisted for eight further weeks until 10 April despite symptomatic treatment. The diagnosis of a presumptive case of MAYV infection diagnosed by serology was established.

\section{Discussion}

To the best of our knowledge, this case is the first published report of MAYV disease in a traveller returning to Europe. The presenting symptoms and signs were almost identical to those reported in previous clinical descriptions of the disease $[2,4,5]$. In this case, the decision to test for a rather exotic virus such as MAYV was based on several factors: the patient's detailed travel history in tropical South America, which allowed risk factors to be identified such as potential exposure to vectors carrying diseases endemic in that area; the clinical presentation with incapacitating arthralgia following acute febrile illness; and finally, the expertise and technical tools available in the specialist clinic for tropical medicine where the patient was treated. Other viral infections with similar clinical presentation and geographical distribution were ruled out by laboratory tests.

The case illustrates the challenge of clinically differentiating MAYV disease from classical dengue fever and other febrile exanthematous diseases that also circulate in South America, as well as the role of laboratory confirmation in establishing a correct diagnosis. Indeed, dengue fever was initially suspected considering its occurrence in most cities and places on tropical America, including the Amazon basin. The pathogenesis of debilitating symptoms in MAYV disease is still a poorly understood phenomenon [5], although persistent infection of synovial macrophages has been documented for other closely related and also arthritogenic alphaviruses [6]. The results of serological studies of the two consecutive convalescent-phase serum samples showed that the patient did not seroconvert with a switch from IgM to IgG. In most acute arboviral infections, IgM class-specific antibodies are generally no longer detectable after a period of 6-12 months post infection $[7,8]$. Considering the period for seroconversion in MAYV infection, we can therefore assume that the time between disease onset and the last late-phase blood sampling in this patient was not long enough for to allow Ig class switching.

Interestingly, this report highlights the need for increased awareness MAYV disease as a differential diagnosis in travellers or migrants returning from endemic areas of tropical South America with febrile illnesses involving peripheral rheumatism and persistent arthralgia. Finally, it illustrates how travellers can act as signals for alert that can provide insights into the risk of transmission of infections in certain geographical areas.

\section{References}

1. Figueirido LTM. Emergent arboviruses in Brazil. Rev Soc Bras Med Trop. 2007;40(2):224-9.

2. Tesh RB, Watts DM, Russell KL, Damodaran C, Calampa C, Cabezas C, et al. Mayaro virus disease: an emerging mosquitoborne zoonosis in tropical South America. Clin Infect Dis. 1999;28(1):67-73. 
3. Sissoko D, Malvy D, Ezzedine K, Renault P, Moscetti F, Ledrans $M$, et al. Post-epidemic chikungunya disease in Reunion Island: course of rheumatic manifestations and associated factors over a 15-month period. PLoS Negl Trop Dis. 2009;3(3):e389.

4. Azevedo RSS, Silva EVP, Carvalho VL, Rodrigues SG, Nunes Neto JP, et al. Mayaro fever virus, Brazilian Amazon. Emerg Infect Dis. 2009;15(11):1830-2.

5. Taylor SF, Patel PR, Herold TJ. Recurrent arthralgias in a patient with previous Mayaro fever infection. South Med J. 2005;98(4):484-5.

6. Jaffar-Bandjee MC, Das T, Hoarau JJ, Krejbich Trotot P, Denizot M, Ribera A, et al. Chikungunya virus takes centre stage in virally induced arthritis: possible cellular and molecular mechanisms to pathogenesis. Microbes Infect. 2009;11(14-15):1206-18.

7. Malvy D, Ezzedine K, Mamani-Matsuda M, Autran B, Tolou $\mathrm{H}$, Receveur MC, et al. Destructive arthritis in a patient with chikungunya virus infection with persistent specific IgM antibodies. BMC Infect Dis.2009;9:200.

8. Weaver SC, Reisen WK. Present and future arboviral threats. Antiviral Res. 2010;85(2):328-45. 
